\title{
The Mechanisms behind Crime Generators and Attractors: A Scoping Review
}

\section{ABSTRACT}

\section{OBJECTIVES}

This scoping review aims to answer the following question: To what extent have the mechanisms behind crime generators and attractors been studied?

\section{METHODS}

This work follows the procedure laid out by the Joanna Briggs Institute for scoping reviews (Tricco, 2017).

\section{RESULTS}

Within the studies included in this review, a great deal of inconsistency in the definitions of crime generators and attractors was found. Moreover, of the 48 papers included, only 11 examined the mechanisms behind crime generators and attractors.

\section{CONCLUSIONS}

This scoping review finds a dearth of research into the mechanisms behind crime generators and attractors. This review suggests three potential reasons for this: the lack of consistent definitions for these types of spaces; challenges identifying suitable datasets and methodologies to study these processes empirically; and the fact that crime generators and attractors are not mutually exclusive.

KEY WORDS: CRIME ATTRACTORS, CRIME GENERATORS, DEFINITIONS, MECHANISMS, SCOPING REVIEW. 


\section{BACKGROUND}

It is well-known that crime is distributed neither uniformly nor randomly in space. On examining the impact of the urban backcloth on crime, Brantingham and Brantingham (1995) identified a potential classification for two types of hotspots based on different types of causal mechanisms: crime generators and crime attractors. Crime generators, they posited, are areas that large numbers of people visit for reasons unrelated to criminal activity, such as public transport hubs. They suggested that potential offenders, who visit the area because of its legitimate use, come into contact with criminal opportunities that they then exploit. Crime generators are not, therefore, areas that are specifically associated with crime. Crime attractors, on the other hand, are areas with reputations for particular illegal activities, such as drug markets, to which suitably motivated offenders are drawn.

Brantingham and Brantingham's (1995) paper was not the first to consider the reason why certain facilities lead to increased crime. Frisbie et al. (1977, cited by Roncek and Maier (1991)), for example, proposed several potential reasons why areas with bars see more crime than those without. These causes include those latterly suggested by Brantingham and Brantingham (1995) as characteristics of crime generators, such as potential offenders being among the bars' clientele, and crime attractors, such as bars attracting motivated offenders in search of targets. Moreover, since the introduction of crime generators and attractors, additional types of hotspot places have since been suggested, such as crime enablers (Clarke and Eck, 2003), crime radiators (Bowers, 2014) and crime absorbers (ibid.). Despite this variety of research on this topic, this work shall focus on Brantingham and Brantingham's (1995) classification of these two types of spaces, due to its consistent prominence in environmental criminology scholarship.

This paper presents the results of a scoping review examining literature on crime generators and attractors. The motivation for this review is threefold. First, there is a dearth of research specifically examining crime generators and attractors, rather than merely referencing them. Although the presence of crime generators has been referred to as "undisputed" (Song et al., 2019 p.832), empirical 
evidence for the existence of crime generators and attractors is limited and is often produced by methods that have limitations (Kurland et al., 2014). In addition to this, the status of a location as either a crime generator or attractor is often suggested as a post-hoc explanation of crime concentration (Davies and Birks, 2021) without much further investigation, leading the concept to be frequently referenced, but relatively under-researched, in environmental criminology. Second, of the research that has been conducted, there is much confusion around what constitutes a crime generator and crime attractor, consequently leading to misuse of terms. Indeed, Newton (2018 p.7) stressed "there is perhaps a need to revisit these definitions". Empirical research into crime generators and attractors is complex, and thus this is not surprising, but future research into this concept would benefit from improved understanding of these spaces. Third, further understanding of crime generators and attractors could have a practical implication if used to tailor crime reduction strategies, as it is possible that crime generators and attractors require different law enforcement strategies (Sosa et al., 2019).

Whilst many of the characteristics of crime generators and attractors are consistent across both types of space, their main difference is the motivation of the offender (Newton, 2018); whether the offence was opportunistic or actively sought. As a result, crime control measures could focus on specific aspects of the offence (Sosa et al., 2019), depending on the type of area in question. Moreover, Frank et al. (2011a) suggest that knowledge of these spaces could aid in creating a profile of offenders. For example, if a crime is committed near a specific crime attractor, law enforcement could identify potential characteristics of the offender based on the facilities that attracted them to that space.

In order to fill these gaps in understanding, this scoping review aims to answer the following question: To what extent have the mechanisms behind crime generators and attractors been studied? In this work, the term "mechanism" refers to the processes underpinning crime generators and attractors, highlighted by Brantingham and Brantingham (1995) in the definitions provided in their seminal paper, which are discussed in Section 3.1. This work has the following objectives: 
1. Investigate the extent to which crime generators and attractors have been researched.

2. Explore how crime generators and attractors have been defined in the existing literature, and how these definitions align with their causal mechanisms as posited by Brantingham and Brantingham (1995) .

3. Examine the extent to which the mechanisms behind generators and attractors have been investigated.

The structure of the review is as follows. Section 2 outlines the methodology, including the search terms, databases used and inclusion and exclusion criteria. Section 3 outlines the results. Section 4 contains a discussion of their implications and recommendations for future research, and Section 5 draws conclusions.

\section{Methodology}

The approach taken to review the literature on crime generators and attractors follows a scoping review (Tricco, 2017), designed to assess the extent of a body of literature (Munn et al., 2018; Tricco, 2017). Based on the procedure laid out by the Joanna Briggs Institute for scoping reviews (Tricco, 2017), the steps taken to conduct the review were as follows. Details on the key stages will be discussed in the coming sections.

1. Development of a protocol for the review, including its methodology.

2. Refinement of research question and objectives.

3. Identification of inclusion and exclusion criteria.

4. Undertaking of the searches in each database.

5. Use of Mendeley software to check for, and remove, duplicates.

6. Supplementary search using Google Scholar.

7. Title and abstract screening using abstrackr website.

8. Full text screening. 
9. Backwards snowball search.

10. Creation of charting form.

11. Data charting.

12. Analysis of data and interpretation of results.

\subsection{Search Strategy}

\subsubsection{Key Words}

Having formulated the research question, the next step was to identify the key words which would be entered into the selected databases. These were:

1. Terms relating to crime generators and attractors: crim*, generator*, attractor*

2. Terms relating to spatial distribution of crime: geog*, distrib*, spatial, pattern*

3. Term relating to the classification of spaces: classif*

\subsubsection{Databases}

Owing to the multi-disciplinary nature of this work, a number of different databases were selected that covered several different fields. These are listed in Table 1, alongside information on the search undertaken in each. Although every effort was made to conduct the same search across each database, there are some differences that are database-dependent and thus unavoidable.

Where possible, each search for the key words was conducted in the title and abstract, rather than the full text. This decision reflects the fact that when these terms were searched for in ProQuest Dissertations in full text, there were over 39,000 results. When the same search was run looking anywhere except full text, only 12 results were identified. This may indicate the extent to which crime generators and attractors are referenced in research, rather than specifically investigated. 


\begin{tabular}{|c|c|c|c|c|}
\hline Database & Search Term & $\begin{array}{l}\text { Location of } \\
\text { Search }\end{array}$ & Data Completed & $\begin{array}{l}\text { Count of } \\
\text { Results }\end{array}$ \\
\hline $\begin{array}{l}\text { Web of } \\
\text { Science Core } \\
\text { Collection }\end{array}$ & $\begin{array}{lr}\text { TS=(crim* } & \text { AND } \\
\text { (generator* } & \text { OR } \\
\text { attractor*) ) } & \text { AND } \\
\text { TS=(classif* OR } & \text { pattern* } \\
\text { OR geog* OR distrib* OR } \\
\text { spatial) }\end{array}$ & $\begin{array}{l}\text { TS = "Abstract, } \\
\text { Title, and/or } \\
\text { Keywords fields of } \\
\text { a record" }\end{array}$ & 09.06 .2020 & 86 \\
\hline Scopus & $\begin{array}{l}\text { ( TITLE-ABS-KEY ( crim*) } \\
\text { AND ( generator* OR } \\
\text { attractor*)) AND ( TITLE- } \\
\text { ABS-KEY ( classif* OR } \\
\text { pattern* OR geog* OR } \\
\text { distrib* OR spatial)) }\end{array}$ & $\begin{array}{l}\text { TITLE-ABS-KEY= A } \\
\text { combined field } \\
\text { that searches } \\
\text { abstracts, } \\
\text { keywords, and } \\
\text { document titles }\end{array}$ & 09.06 .2020 & 896 \\
\hline $\begin{array}{l}\text { JSTOR: } \\
\text { Criminology } \\
\text { and Criminal } \\
\text { Justice }\end{array}$ & $\begin{array}{l}\text { ((crim* AND (generator* } \\
\text { OR attractor*)) AND } \\
\text { (classif* OR pattern* OR } \\
\text { geog* OR distrib* OR } \\
\text { spatial)) }\end{array}$ & All & 10.06 .2020 & 103 \\
\hline $\begin{array}{l}\text { JSTOR: } \\
\text { Geography }\end{array}$ & $\begin{array}{l}\text { ((crim* AND (generator* } \\
\text { OR attractor*)) AND } \\
\text { (classif* OR pattern* OR } \\
\text { geog* OR distrib* OR } \\
\text { spatial)) }\end{array}$ & All & 10.06 .2020 & 127 \\
\hline $\begin{array}{l}\text { JSTOR: } \\
\text { Sociology }\end{array}$ & $\begin{array}{l}\text { ((crim* AND (generator* } \\
\text { OR attractor*)) AND } \\
\text { (classif* OR pattern* OR } \\
\text { geog* OR distrib* OR } \\
\text { spatial)) }\end{array}$ & All & 10.06 .2020 & 1,545 \\
\hline JSTOR: Law & $\begin{array}{l}\text { ((crim* AND (generator* } \\
\text { OR attractor*)) AND } \\
\text { (classif* OR pattern* OR } \\
\text { geog* OR distrib* OR } \\
\text { spatial)) }\end{array}$ & All & 10.06 .2020 & 1,325 \\
\hline $\begin{array}{l}\text { ProQuest: } \\
\text { Applied } \\
\text { Social } \\
\text { Sciences } \\
\text { Index and } \\
\text { Abstracts } \\
\text { (ASSIA) }\end{array}$ & $\begin{array}{l}\text { ((crim* AND (generator* } \\
\text { OR attractor*)) AND } \\
\text { (classif* OR pattern* OR } \\
\text { geog* OR distrib* OR } \\
\text { spatial)) }\end{array}$ & $\begin{array}{l}\text { "Anywhere } \\
\text { except full text" }\end{array}$ & 09.06 .2020 & 11 \\
\hline $\begin{array}{l}\text { ProQuest: } \\
\text { Dissertations }\end{array}$ & $\begin{array}{l}\text { ((crim* AND (generator* } \\
\text { OR attractor*)) AND }\end{array}$ & $\begin{array}{l}\text { "Anywhere } \\
\text { except full text" }\end{array}$ & 09.06 .2020 & 12 \\
\hline
\end{tabular}




\begin{tabular}{|c|c|c|c|c|}
\hline $\begin{array}{l}\text { and Theses } \\
\text { A\&I }\end{array}$ & $\begin{array}{l}\text { (classif* OR pattern* OR } \\
\text { geog* OR distrib* OR } \\
\text { spatial)) }\end{array}$ & & & \\
\hline $\begin{array}{l}\text { ProQuest: } \\
\text { Sociological } \\
\text { Abstracts }\end{array}$ & $\begin{array}{l}\text { ((crim* AND (generator* } \\
\text { OR attractor*)) AND } \\
\text { (classif* OR pattern* OR } \\
\text { geog* OR distrib* OR } \\
\text { spatial)) }\end{array}$ & $\begin{array}{l}\text { "Anywhere } \\
\text { except full text" }\end{array}$ & 09.06 .2020 & 29 \\
\hline $\begin{array}{l}\text { Google } \\
\text { Scholar }\end{array}$ & "crime attractor" & Title & 22.06 .2020 & 0 \\
\hline $\begin{array}{l}\text { Google } \\
\text { Scholar }\end{array}$ & "crime attractors" & Title & 22.06 .2020 & 19 \\
\hline $\begin{array}{l}\text { Google } \\
\text { Scholar }\end{array}$ & "crime generator" & Title & 22.06 .2020 & 2 \\
\hline $\begin{array}{l}\text { Google } \\
\text { Scholar }\end{array}$ & "crime generators" & Title & 22.06 .2020 & $\begin{array}{l}22 \quad \text { (12 of } \\
\text { which were } \\
\text { already } \\
\text { included from } \\
\text { previous } \\
\text { Google } \\
\text { Scholar } \\
\text { searches) }\end{array}$ \\
\hline
\end{tabular}

Table 1 - Details of the Database Searches

Through the use of these databases, some grey literature was included, such as conference proceedings and PhD theses. Of the final 48 articles included in the analysis, 6 were from grey literature sources.

\subsubsection{Backwards Snowball Search}

Following the full text screening, a backwards snowball search was undertaken to identify any relevant papers which were referenced by those included in this review. For this, the reference list of each article included was examined, and those papers that had "generator(s)" or "attractor(s)" in the title were incorporated for further screening. 


\subsection{INCLUSION AND EXCLUSION CRITERIA}

Once the searches had been conducted, title and abstract screening was undertaken by one reviewer (the author). Whilst it is best practice to have multiple reviewers for scoping review screening (Munn et al., 2018), this was beyond the resources of this work as it was conducted as part of PhD research. Each article was then considered against the predefined inclusion and exclusion criteria. These are as follows:

\begin{tabular}{|c|c|}
\hline Inclusion Criteria & Exclusion Criteria \\
\hline $\begin{array}{l}\text { Crime generators or attractors must be the clear } \\
\text { focus of the narrative, or a section of the } \\
\text { narrative. }\end{array}$ & Studies not in English \\
\hline $\begin{array}{l}\text { The studies do not have to be investigating } \\
\text { "traditional" crime generator or attractor } \\
\text { examples (such as those given as examples by } \\
\text { Brantingham and Brantingham (1995)), but } \\
\text { must identify crime generators or attractors as } \\
\text { the focus of the research, regardless of the case } \\
\text { study facility under scrutiny. }\end{array}$ & $\begin{array}{l}\text { Studies only looking for hotspots that are not } \\
\text { focused on crime generators or attractors }\end{array}$ \\
\hline $\begin{array}{l}\text { The research does not have to exclusively study } \\
\text { crime generators or attractors. }\end{array}$ & $\begin{array}{l}\text { Studies which refer to crime generators or } \\
\text { attractors in a throwaway manner, without } \\
\text { researching them directly }\end{array}$ \\
\hline $\begin{array}{l}\text { The studies can be empirical, theoretical or } \\
\text { computational. }\end{array}$ & Book reviews \\
\hline $\begin{array}{l}\text { There are no restrictions of time or location of } \\
\text { study. }\end{array}$ & Undergraduate or master's level theses \\
\hline
\end{tabular}




\begin{tabular}{|l|l|}
\hline There are no restrictions on crime type studied. & $\begin{array}{l}\text { Studies that use crime generators or attractors } \\
\text { to represent opportunity rather than studying } \\
\text { them specifically }\end{array}$ \\
\hline
\end{tabular}

Table 2 - Inclusion and Exclusion Criteria

These inclusion and exclusion criteria are suited to identifying papers which specifically studied crime generators and attractors, which is the aim of this work. However, they could lead to the exclusion of other papers studying elements of these spaces, such as those looking at more general crime concentration, or those which study the mechanisms without specifically declaring their paper to be investigating these spaces. Whilst this is a limitation of this approach, and the review would have been more comprehensive if they were included, the focus of this review is to examine work which has specifically studied these spaces, in part to examine the extent to which they have been the focus of research. As a result, these inclusion and exclusion criteria are considered appropriate for this study.

\subsection{DATA CHARTING}

A data charting form was created used Google Forms to permit consistent data extraction. It covered areas such as whether the research looked at crime generators or attractors (or both), whether the paper examined the mechanisms behind these spaces, and the methods employed. A full list of the fields in the charting form is available in Appendix A.

\section{RESULTS}

Through conducting this scoping review, 48 papers were identified as eligible for inclusion. Figure 1 , below, uses a PRISMA template to provide an overview of the number of references obtained at each step of the search process. A complete list of the 48 references is included in Appendix B. 


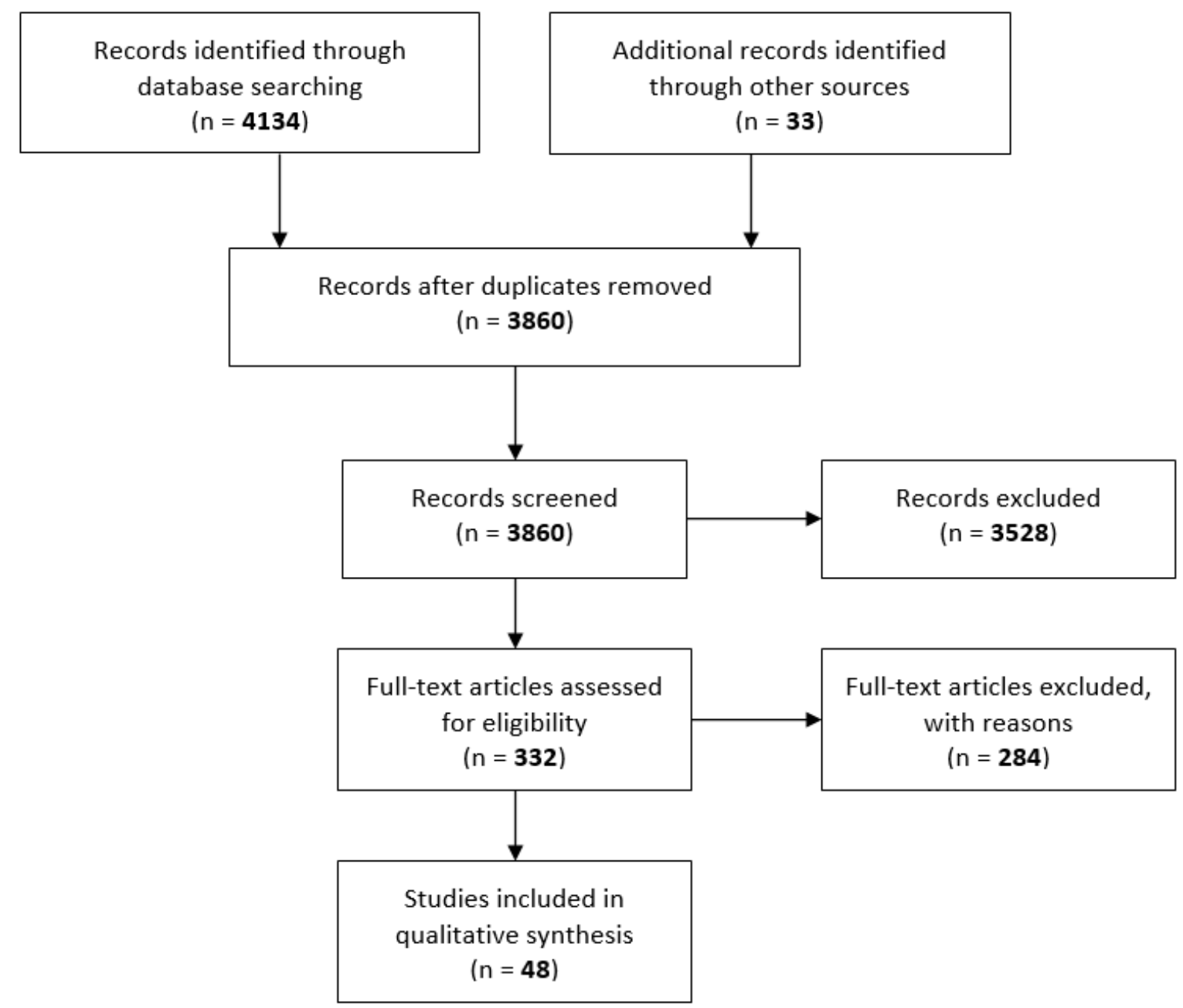

Figure 1 - Flowchart of Stages of the Review

\subsection{Defining Crime Generators and ATtRactors}

Although Brantingham and Brantingham (1995) provide definitions of both crime generators and attractors in their seminal paper which are reiterated shortly, these definitions are not used consistently by researchers. The definitions provided in the papers included in this review shall now be examined, in order to assess how the concept of crime generators and attractors has been interpreted, and therefore developed, by these authors, and how they relate to the original definitions provided. 


\subsubsection{Crime Generators}

The original definition for crime generators given by Brantingham and Brantingham (1995) is as follows:

"Crime generators are particular areas to which large numbers of people are attracted for reasons unrelated to any particular level of criminal motivation they might have or to any particular crime they might end up committing... Mixed into the people gathered at generator locations are some potential offenders with sufficient general levels of criminal motivation that although they did not come to the area with the explicit intent of doing a crime, they notice and exploit criminal opportunities" (Brantingham and Brantingham, 1995 p.7)

Whilst this definition appears straightforward (Newton, 2018), the papers included in this review saw a number of variations on this original concept. To explore this variation, this section will start by identifying the core elements of the Brantingham and Brantingham (1995) definition of a crime generator. This work shall then discuss those papers which followed this original definition, followed by those which did not provide a complete definition, or failed to define them at all, before discussing those papers which used a definition which differs from that suggested by Brantingham and Brantingham (1995).

In establishing a definition for a crime generator which is in line with Brantingham and Brantingham's (1995), it was important to identify the key mechanisms proposed in their original definitions. Through examining their paper, three fundamental elements were suggested to explain crime concentration at crime generators: (1) the idea of large numbers of people using the space, (2) the fact that the offenders do not visit the space specifically to commit a crime, but encounter serendipitous criminal opportunities, and (3) that the space is not criminogenic in itself; it does not specifically lead to criminal behaviour. 
A number of papers included in this review were found to provide definitions that mentioned all of these fundamental elements, including Contreras (2017), Demeau and Parent (2018) and Groff and McCord (2012). However, this list also highlighted a number of papers which did not define crime generators as thoroughly as in the seminal paper. Yoo and Wheeler (2019 p.2), for example, stated that "Places with a larger number of individuals (the denominator) are often referred to as crime generators". Whilst this is not untrue, as the first element highlighted above concerns the large quantity of people at the location, one can argue that this is not sufficient for a definition of a crime generator, as it misses the two other fundamental elements proposed by Brantingham and Brantingham (1995). Similarly, Song et al. (2019 p.833) claimed that "crime generators produce crime because they are widely known and because they provide abundant opportunities". Whilst, as before, this is not necessarily incorrect, this suggestion misses the second and third factors in the list above. Moreover, one could argue that crime generators do not produce crime concentration because they are "widely known", but rather because they are widely used.

Besides these examples, a number of other articles miss one of the points suggested above but incorporate the remaining two. Some, for example, did not include the second point; that the crimes committed at crime generators are primarily opportunistic, including Irvin-Erickson and La Vigne (2015), Drawve et al. (2016) and Adams and Felson (2015). Others, such as Tillyer et al. (2020), Song et al.( 2017) and Feng et al. (2019) omit the third element; that crime generators are not criminogenic. Finally, a number of papers did not provide definitions at all. Whilst some authors seemingly excluded their definition as their research was focused on crime attractors (for example Hewitt et al. (2018), Iwanski et al. (2012) and Reid et al. (2014)), others neglected to provide a definition, despite researching factors concerning crime generators, including Kimpton et al. (2017), Tita and Ridgeway (2007) and McCord and Ratcliffe (2007). Additionally, Han et al. (2019) provided an inaccurate definition for both crime generators and attractors by not separately defining them ("certain facilities play a role of generator or attractor of crime by attracting large numbers of people that may likely be 
victims or offenders" (Han et al., 2019 p.8)). Whilst this could be considered to include elements of definitions for both crime generators and crime attractors, as defined later, it does not specifically cover any of the three points for a definition for a crime generator which is in keeping with Brantingham and Brantingham's (1995) original concept.

As well as absent and incomplete definitions, there were also a number of papers identified through the review methodology that did not align their definition with the mechanisms highlighted above. Sheard (1998 p.1), for example, referred to crime generators as "centers for drugs and crime", and LeBeau (2012) claimed that crime generators are "establishments used as a bases [sic] for criminal activities". Besides these irregular definitions, which do not appear to be in line with the mechanisms highlighted in Brantingham and Brantingham's (1995) work, Breetzke et al. (2019, no page) consider crime generators to be "places to which strongly motivated, intending criminal offenders migrate to because of opportunities for crime", which is notably more in keeping with the original definition given for a crime attractor (Brantingham and Brantingham, 1995), and does not appear to have any of the features of a crime generator definition. As a result, the focus of work in Breetzke et al.'s (2019) paper is hereafter referred to as crime attractors.

\subsubsection{Crime Attractors}

In order to explore the definitions provided for crime attractors, it is important to first examine their original definition, which shall be used to create an outline highlighting their key mechanisms:

"Crime attractors are particular places, areas, neighbourhoods, districts which create wellknown criminal opportunities to which strongly motivated, intending criminal offenders are attracted because of the known opportunities for particular types of crime" (Brantingham and Brantingham, 1995 p.8)

From Brantingham and Brantingham's (1995) definition above, the following elements are proposed as integral to a definition of a crime attractor: (1) the reputation of the space as offering criminal opportunities, and (2) the fact that motivated offenders visit them with the specific goal of committing 
crime. Using these proposed mechanisms, a number of papers provided definitions which were in keeping with Brantingham and Brantingham's (1995) original idea, including LaRue and Andresen (2015), Bowers (2014) and Song et al. (2017).

Using this outline, a definition was considered incomplete if it referred to only one mechanism of the two specified. Of the papers examined in this review, four articles overlooked one component. Yoo and Wheeler (2019 p.3), for example, stated "Due to more vulnerable targets within a location, it may be that motivated offenders are attracted to particular areas to commit a crime". Whilst the second element of the schema, that concerning the luring of motivated offenders to the space, is clearly included, the first, regarding the reputation of the area, is absent. McCord et al.'s (2007) and Piza and Gilchrist's (2018) definitions also have the same flaw. Boessen and Hipp (2018), on the other hand, refer to the reputation of crime attractors, but exclude the concept of drawing the offenders to them.

A number of papers, such as that by Kimpton et al. (2017), Sheard (1998), and Vandeviver et al. (2019), omitted a definition for crime attractors due to their studies' focus on crime generators. Some, on the other hand, neglected to define crime attractors despite their research focusing on them, including Hewitt et al. (2018) and Xu and Griffiths (2017).

Moreover, some papers provided definitions for crime attractors which are not in line with the definition discussed above. Both Song et al. (2013) and LeBeau (2012), for example, primarily defined attractors as spaces that provide attractive targets for offenders, overlooking both of the factors in the schema. Interestingly, however, LeBeau (2012) acknowledges that their definition is dissonant with that provided by Brantingham and Brantingham (1995). Malleson and Andresen (2016 p.58) also neglect to incorporate either of these elements into their definition, instead referring to crime attractors as "places that are used specifically for criminal activity", further confusing the concepts.

\subsection{CAusal MeChanisms of CRIME Generators and Attractors}

In order to better understand crime generators and attractors, it is important to develop understanding of the proposed causal mechanisms underpinning them. As a result, this work shall 
look into those papers that specifically explored the elements that would lead to the emergence of a hotspot at a crime generator or attractor, as defined by the definitions outlined above. Despite the importance of the mechanisms at work, only 11 of the 48 papers examined here discussed them, their second order implications, or elements relating to them. In this section, the contributions that these 11 papers made to understanding of these concepts shall be discussed.

Two papers in this review specifically discussed the mechanisms behind crime generators. Firstly, Newton (2018) discussed the notion of busy-ness at crime generators in his textbook-style paper. The author suggested that a number of factors need to be considered when discussing this, including the number of people in the space, the density of people in the space, and the length of time they are together. Secondly, Vandeviver et al. (2019) explored the criminogenic effects of stadiums as crime generators, to investigate whether they generate crime only on days when they are used, or if they also provide opportunities which can then be revisited. They identified that stadiums experience both immediate and delayed crimes, and suggested that these two types of criminogenic effect are conceptually distinct. Whilst Brantingham and Brantingham (1995) did note this potential distinction at crime generators, this was not discussed at length and thus benefits from this investigation and empirical support.

As well as these papers on crime generators, five articles examined crime attractor mechanisms. Song et al. (2013), for example, in their work into the relationship between crime attractors and mobility, developed understanding of crime attractors by noting that crime attractors do not necessarily lead to crime occurring uniformly around a central point. Instead, they posit, their connection to major pathways leads to the emergence of crime ridges that can connect crime attractor sites. Similarly, both Frank et al. (2011b) and Mago et al. (2014) also consider the impact of attractors on each other. Both examine the attractiveness of shopping malls as crime attractors, with Frank et al. (2011b) focusing on the strength of attraction around malls and Mago et al. (2014) studying relative attractiveness of multiple crime attractors. Despite their slightly different focus, both of these articles conclude that 
the presence of multiple crime attractors can change the impact of each. Frank et al. (2011b), for example, identify that malls have different levels of attractiveness depending on their size, with smaller malls acting as weaker crime attractors. They also explore the consequences of the addition of crime attractors in an area, concluding that this addition does not affect all crime attractors equally. Mago et al. (2014), on the other hand, stress that relative attractiveness is subject to a number of factors, finding that stronger attractors were those with better transport links, a wider range of services and in more central locations, rather than purely related to size. Iwanski et al. (2012) also identify that multiple factors contribute to a site's relative attractiveness, including size, accessibility and the criminogenic nature of the surrounding area.

Moreover, both Iwanski et al. (2012) and Frank et al. (2011a) examined offenders' journeys to crime attractors. Iwanski et al. (2012), for example, investigated the impact of crime attractors along a route, rather than the impact at the destination itself, concluding that crime attractors are not necessarily a single node, but rather raise the attractiveness of the whole area in which they are located. Frank et al. (2011a) reach a similar conclusion from their research. By identifying clusters of criminals' intersections, they identify these as potential locations of crime attractors, but stress that the crime attractor is not a single point, but encompasses the surrounding area as well. Whilst this method identified three malls as crime attractors, the authors highlight that not all malls created clusters that were indicative of crime attractors, and therefore not all of a certain facility type could be classified as such.

In addition to these papers that considered the mechanisms of either crime generators or crime attractors, five papers examined them in tandem. Among them is that of Brantingham and Brantingham (1995), who introduced the concept and the mechanisms, demonstrating them empirically as well as theoretically.

A number of papers explored methods of classifying spaces as either crime generators or attractors based on their mechanisms. Both Kurland et al. (2014) and Irvin-Erickson and La Vigne (2015), for 
example, used methods and variables derived from these mechanisms for their classifications. Similarly, Boivin and D'Elia (2017) tried to distinguish between the two types of space based on measures for risk, effort and reward using methods underpinned by these mechanisms. Whilst some could argue that this means that understanding of the mechanisms themselves is not being explored and developed, but rather used to test pre-conceived ideas of crime generators and attractors, empirical work such as this could be used as a method of testing and validating these concepts.

To summarise, whilst research into the mechanisms underpinning crime generators and attractors would be incredibly beneficial, it appears that comparatively little work has been undertaken on it, especially for crime generators. As a result, there can be little surprise when authors use irregular definitions or methods to study them, when the foundations for understanding this idea are somewhat limited. If the concept of crime generators and attractors is to be developed further than merely a post-hoc explanation of crime concentration (Davies and Birks, 2021), further understanding is required into these underlying processes.

\section{DISCUSSION}

This scoping review aimed to examine papers that explored the concept of crime generators and attractors to answer the following question: To what extent have the mechanisms behind crime generators and attractors been studied? In order to answer this question, each of the objectives of this review shall be discussed before suggestions for further research and a final conclusion.

\subsection{To What Extent Have Crime Generators and Attractors Been Studied?}

Through this review, it has been identified that crime generators and attractors, although often referred to in environmental criminology, have been relatively understudied. Whilst a great many papers refer to these types of spaces, the number of those that focus on verifying the mechanisms that might underpin them, is far lower. Indeed, of the papers that were included here, not all aligned their work with the mechanisms of crime generators and attractors put forward by Brantingham and 
Brantingham (1995). This will be discussed in more depth in Section 4.3, but this also calls into question the extent of the scholarship on this topic. Although general studies into these spaces are beneficial to the field, it is possible that further understanding of these mechanisms would extend the breadth and depth of this topic, and indeed go further in confirming the validity of the concept or the need for its refinement.

This lack of research was demonstrated through the aforementioned search in ProQuest Dissertations; when searched in full text, the search terms resulted in more than 39,000 papers, compared to only 12 when run anywhere except full text. This succinctly illustrates why more research is required examining crime generators and attractors and their mechanisms; although this concept is referred to a great deal, there has been very little research verifying the processes proposed. This is not only a problem theoretically, as it leads to potentially unsubstantiated claims for locations of these types of spaces, but identifying a crime cluster and simply allocating it to one of these classifications without exploring it could also lead to practical limitations for law enforcement. Not only could the mechanisms underpinning crime generators and attractors not be at play in that location, and thus the location be incorrectly classified, but there may be processes leading to a different type of crime cluster which is currently unidentified. By labelling this site a crime generator or attractor, these unidentified mechanisms could remain unknown.

One could ask why this is the case; why are crime generators and attractors so often used as a posthoc explanation for an area of crime concentration (Davies and Birks, 2021) with little research into the concept itself? Firstly, this lack of research could be caused by the seemingly self-explanatory nature of crime generators and attractors. When one examines the mechanisms proposed by Brantingham and Brantingham (1995), they appear easily understood; that crime concentration occurs either where there are a lot of potential targets, or where motivated offenders go because they want to commit crime. As a result of this apparent simplicity, it is possible that researchers feel they have sufficient understanding into these spaces to use these monikers without researching them 
further. Secondly, it could be the result of previous researchers setting a precedent. If it has become the norm that crime concentrations can be attributed to a crime generator or attractor without much research, this could be seen as common practice and therefore acceptable. Thirdly, it could be because it is challenging to empirically verify these mechanisms. It is difficult to obtain appropriate data to empirically examine these processes, resulting in limited ways in which to test them. As a result, this concept has remained largely unverified and potentially misunderstood. This is discussed in greater length in the coming section. Despite these potential explanations, it is surprising that this issue is so prevalent.

Is it possible, however, that all crime hotspots are in fact caused by the mechanisms behind crime generators or attractors, and consequently this frequent use of these labels is correct? One must consider whether there are other mechanisms that could lead to the concentration of crime, or whether those suggested by Brantingham and Brantingham (1995) are applicable to all possible hotspots. This, however, seems unlikely. Not only have other types of hotspots been proposed (such as crime enablers (Clarke and Eck, 2003)), but there must also be consideration for other mechanisms that have yet to be formally hypothesized. For example, a crime hotspot could emerge where lots of opportunistic crimes occur which are not necessarily related to large numbers of people being present. This sort of hotspot could not be classified as either a crime generator or an attractor but is conceivable if small numbers of victims are repeatedly victimized in the same place, for example. As a result, it seems unlikely that all areas of crime concentration could be considered as crime attractors or generators, and thus these labels should be researched further.

\subsection{How Have Crime Generators and Attractors been Defined?}

This research has demonstrated that Brantingham and Brantingham's (1995) original definitions have been open to much interpretation in later work. In this review, the key components of the definitions of both a crime generator and crime attractor were formalised, and each definition in the papers included in this review were then compared against this formalisation. Doing so, it was identified that 
whilst some articles defined crime generators and attractors in keeping with the mechanisms proposed in the seminal paper, a number of others gave definitions that were either incomplete or inconsistent with those originally proposed. As a result, when one explores the definitions of crime generators and attractors the main conclusion is one of inconsistency, as the definitions provided by the authors vary a great deal between papers. But what could be the cause of this disparity? Two potential explanations have been identified.

Firstly, variation could be the result of previous researchers examining crime generators and attractors without providing accurate definitions. Even in the articles examined here, that were included in this study because of their focus on crime generators and attractors, a variety of different definitions were provided. Indeed, of the 48 papers included in this review (of which one is the original Brantingham and Brantingham (1995) paper), 15 did not reference the seminal work while providing their definitions of the spaces. Whilst an inaccurate definition, or an absent one, does not lead one to automatically assume limited understanding of the topic, it is far from the gold standard if the variation from the original concept is not justified. As stated previously, the concept of crime generators and attractors, and the terminology used, is not without confusion (Newton, 2018). Neglecting to define these concepts accurately could lead to further misinterpretation, consequently solidifying further misuse. Moreover, in papers where the term has been so inaccurately defined, the authors' understanding of crime generators and attractors is called into question, as is the validity of the conclusions of the paper. The use of inaccurate definitions such as these threatens to further confuse the terminology behind crime generators and attractors, as well as potentially diluting the literature base if future researchers base their work on these interpretations. As a result, it is recommended that future work follows the formalisation above when defining these spaces, to ensure that the research is in line with Brantingham and Brantingham's (1995) original concepts and mechanisms. Although it is possible that these original definitions were overly simplified, and thus other definitions could be more useful when examining crime concentration, it seems sensible that these original concepts need to be tested first. Rigorous testing of these initial ideas, through analysis 
of the mechanisms outlined above, will enable potential gaps in the definitions to be identified, which could allow development of the definitions in response to this additional evidence. Improving understanding of the definitions of crime generators and attractors will not only aid in theoretical comprehension, but it will also assist in the development of methods to empirically identify these spaces in the real world, as it will lead to greater clarity of the components of each which can be explored. As long as the definitions of these types of spaces remain contentious, challenges will persist in classifying a real-world location as either a crime generator or a crime attractor.

Secondly, these disparities might be caused by the fact that crime generators and attractors are challenging to identify empirically. Not only does this lead to further confusion about their underlying theory, but also means that testing and verifying these mechanisms is challenging. Given that the primary difference between these two types of spaces is offender motivation (Newton, 2018), it is necessary to obtain data on this highly complex topic to accurately differentiate between them empirically. Whilst some have attempted to use proxies for this (such as Sosa et al.'s (2019) variable of 'magnetism', which represented the attractiveness of a casino for crime), this could be most accurately achieved through qualitative work. Indeed, one could question whether proxies such as this accurately reflect offender motivation or merely target attractiveness. However, methods such as interviews with offenders were not used in any of the papers examined in this review. Not only is empirical evidence for the classification of spaces as either crime generators or attractors therefore limited (Kurland et al., 2014), but the two spaces often share many of the same features (Newton, 2018; Song et al., 2019), and can be hard to differentiate in reality (Yoo and Wheeler, 2019). Indeed, this was recognised by Brantingham and Brantingham (1995) in their original paper, who highlighted that spaces are unlikely to be purely crime generators or attractors. As a result, challenges in empirically identifying them and distinguishing between the two could lead to challenges in defining them. 


\subsection{To What Extent Have Crime Generators' and Attractors' Causal Mechanisms BEEN STUDIED?}

Not only were crime generator and attractor mechanisms missing from several of the definitions provided, they were also absent from the research in many of the papers examined here. Whilst a wide range of work was undertaken across the papers included in this review, the analysis was rarely specific to the mechanisms, their characteristics or their second order implications. This means that although a breadth of knowledge has been gained concerning a wide range of locations potentially acting as crime generators or attractors, there is little depth of understanding of these processes. Of those papers that did explore these mechanisms $(n=11)$, this was done in a variety of ways that were discussed above. Whilst some papers were fairly unique in their angle, other ideas were used in multiple studies. Several papers, for example, explored the impacts of multiple crime attractors near each other, and others examined offenders' journeys to crime attractors. Additionally, a number of papers used elements of these mechanisms to explore methods of classifying spaces as either crime generators or attractors.

Three potential causes for the lack of research into these mechanisms could be suggested. Firstly, the aforementioned problem of inconsistently defining crime generators and attractors could lead to confusion and misunderstanding of which mechanisms are actually at play in these locations. Until a consistent definition for these spaces can be identified, it is unsurprising that research into these processes is minimal. This paper has attempted to formalise the processes specified in these original definitions, but this wide range of interpretations suggests that the mechanisms are unclear. Secondly, could this dearth of research be caused by challenges in identifying datasets and methodologies to appropriately study and verify these purported processes? Not only do the crime data have to be at a fine level of geographic accuracy, research into this area would also require data on the motivation of the offender, which is not easily obtained. It is possible that more research could have been conducted on these mechanisms if they were easier to quantify. However, as technology and access to novel datasets develops over time, it is possible that this will present less of a problem for the field. Thirdly, 
as Brantingham and Brantingham (1995 p.9) stressed in their seminal paper, places are "unlikely to be pure attractors or pure generators". This notion further complicates this idea, which is already challenging to investigate, as even with appropriate definitions, datasets and methodologies, it will be impossible to know the extent to which a location has elements of each of these mechanisms.

Despite these challenges, further understanding of crime generators and attractors will not be possible until these mechanisms have been examined. This review has identified that within the extant literature there is limited research ascertaining if these proposed mechanisms are indeed at play at crime hotspots, particularly concerning crime generators. Whilst a small number of the papers examined here found crime concentration in areas where crime attractor mechanisms were proposed to be occurring, research exploring crime generator mechanisms was even more limited. Until these processes have been appropriately tested, we cannot know that these sorts of crime hotspots emerge or affect crime patterns in the manner in which they are theorized to, thus throwing doubt over the existence of crime generators and attractors in the guise in which Brantingham and Brantingham (1995) proposed.

\subsection{FUtURE RESEARCH RECOMMENDATIONS}

Through conducting this scoping review, a number of research gaps have been identified, starting with a dearth of studies testing the mechanisms underpinning crime generators and attractors. Not only would this enable the verification, or refutation, of this concept, but this would also enable appropriate definitions for these types of spaces to be identified. When considered in tandem, it is hoped that verifying the processes posited for crime generators and attractors, alongside improving the definitions for these types of spaces, will lead to improved scholarship in this field.

In addition to these recommendations around basic comprehension of the topic, this scoping review has led to speculation on three additional elements of the concept of crime generators and attractors that could benefit from being explored. Firstly, which characteristics of locations enable the crime generator and attractor mechanisms to turn these sites into crime hotspots? When examining 
locations that are given as examples of crime generators and attractors, it is evident that not all facilities of that type lead to crime concentration. For example, this was highlighted by Frank et al. (2011a) in their study of shopping malls as crime attractors, who identified that not all shopping malls lead to crime patterns indicative of the crime attractor mechanisms at play, and Groff and McCord (2012), who found that whilst some parks appear to be crime generators, the relationship between parks and crime varies between sites. This suggests that the processes that lead to the emergence of a crime generator or crime attractor do not affect all facilities in the same way. One must question, therefore, what characteristics of a site contribute to the development of a crime generator or attractor? Whilst the characteristics affecting the strength of a crime attractor were discussed by several authors in this review (including Frank et al. (2011b); Iwanski et al. (2012) and Mago et al. (2014), those for crime generators were only considered by Tillyer et al. (2020), who explored the features that can moderate the effect of crime generators on offences and Irvin-Erickson and La Vigne (2015) who examined crime generating- and attracting-characteristics of metro stations. Moreover, is it possible that these characteristics can lead to subtypes of crime generators and attractors? If these contextual factors do affect the way in which the crime generator and attractor mechanisms lead to crime hotspots, it could be that these two types of spaces are umbrella terms for a wider classification of types of crime concentration. If this is the case, this could be of interest both theoretically and practically, if crime reduction strategies could be tailored to more specific mechanisms.

Similarly, a second area of research that would be of interest to the field relates to types of crime attractors. Whilst the "traditional" idea of a crime attractor is an area with a reputation for criminal opportunities that lures motivated offenders, it has been suggested that a crime generator can transition into a crime attractor and take on these characteristics as its reputation worsens (Clarke and Eck, 2003). Although it could be argued that the mechanisms underpinning both a traditional crime attractor and this "transition attractor" are the same, this is not necessarily the case. For example, is it reasonable to assume that this new "transition attractor" still experiences opportunistic offences committed by those using the site the way in which a crime generator location is traditionally 
used, therefore taking on mechanisms of both types of spaces? Or, as the reputation of this transition attractor worsens, do people stop using the site for its original purpose, as suggested by Clarke and Eck (2003)? If this is the case, can the site remain a crime attractor if the original target pool has disintegrated? Unless the type of crime that lures offenders to the site has shifted, it seems unlikely that the mechanisms underpinning a crime generator can transition entirely into those of a crime attractor.

Thirdly, the relationship between crime generators and attractors and types of crime would be an interesting topic for further study. When these types of spaces are discussed in the literature, the term "crime" is often used generally, with little distinction as to the type of offence taking place there. Indeed, whilst some of the papers studied here mentioned that crime generators and attractors could experience different types of crime, this tended to be more in passing than at any length (see, for example, Boessen and Hipp (2018), Bowers (2014) and Demeau and Parent (2018)). Despite this, Brantingham and Brantingham (1995) refer to crime generators as "settings that are conducive to particular types of criminal acts" (Brantingham and Brantingham, 1995 p.7, emphasis added), and to crime attractors as "particular places... [to which] intending criminal offenders are attracted because of the known opportunities for particular types of crime" (Brantingham and Brantingham, 1995 p.8, emphasis added). As a result, one can conclude that the type of crime that takes place at both of these spaces is highly specific to that area. Moreover, upon examining the mechanisms behind these two types of locations, it can be suggested that the processes underpinning crime generators and attractors could lead to hotspots for different types of crime (Bowers, 2014; Newton, 2018). Crime generators, for example, regardless of the type of facility being examined, would see a great deal of opportunistic crime which need a large target pool, such as pick pocketing. Crime attractors, on the other hand, would experience large amounts of crime that would require targets to be more actively sought, such as arson. When considering the types of crime that would take place at crime attractors, it seems reasonable to suggest that some crime attractors would be areas which have reputations for highly specific types of crime. As a result, the crime concentration that occurs at these locations, and 
indeed at crime generators, could be specific to a certain type of crime. Furthermore, as pointed out by Newton (2018) and Irvin-Erickson and La Vigne (2015), it is possible that a location is a crime generator or attractor for a specific crime at a specific time of day, or by Brantingham and Brantingham (1995) that a site can be a crime generator for one type of offence but a crime attractor for another. Further study of crime types at these locations could be a valuable avenue for future research, as potential crime generator and attractor sites could have been missed if analysis focuses purely on concentration of all offenses, rather than identifying hotspots of specific crime types.

\section{CONCLUSION}

To conclude, one must re-examine the research question: To what extent have the mechanisms behind crime generators and attractors been studied? This review has identified a dearth of work to support the mechanisms proposed, and therefore limited evidence to confirm the occurrence of these processes at crime hotspots. As a result, this could call into question the existence of crime generators and attractors as hypothesized by Brantingham and Brantingham (1995). Three potential reasons for this paucity of research were suggested; appropriately defining these types of spaces; identifying suitable datasets and methodologies to verify these mechanisms; and the fact that spaces are rarely exclusively either crime generators or crime attractors. Indeed, the challenge of studying crime generators and attractors empirically emerged several times throughout this research and remains one of the largest hurdles for developing understanding of this concept. 


\section{APPENDIX A: FIELDS INCLUDED IN DATA CHARTING}

Administrative fields:

- Date of data extraction

- Paper title

- Author(s)

- Year of publication

- $\mathrm{DOI}$

- Type of publication (journal article, book chapter etc)

Study characteristics fields:

- Brief description of study

- Aims/objectives of study

- Where is the study based (geographically)?

- Looking at crime generators/attractors/both

- Type of facility examined

- Justification for this as a crime generator/attractor

- What crime types were examined?

- What crime data was used?

- When was the crime data from?

- Number of facilities examined

- Where was the facilities data from?

Content fields:

- Does this paper look at crime distribution around a crime generator/attractor?

- If it does look at the crime distribution, what does it find? 
- Does this paper try to classify crime generators/attractors?

- If it does classify crime generators/attractors, how does it do this and what does it find?

- Does this paper advance understanding of the mechanisms of crime generators/attractors?

- If it does look at the mechanisms of crime generators/attractors, what does it find?

Analysis and Results fields:

- What methods of analysis do the authors of this paper use?

- What were their key results?

- How does this work advance knowledge on crime generators/attractors?

- Any other important comments?

Definition fields:

- Do the authors reference the Brantingham and Brantingham (1995) paper when defining generators/attractors?

- Crime generator definition

- Crime attractor definition 


\section{APPENDIX B: REFERENCES INCLUDED IN REVIEW}

1. Adams, W., Felson, M., 2015. Are Parks Crime Generators? An Exploratory Analysis of Crime and Parks in Houston, Texas. DOI: 10.13140/RG.2.1.4730.8005

2. Bernasco, W., Block, R., 2011. Robberies in Chicago: A Block-Level Analysis of the Influence of Crime Generators, Crime Attractors, and Offender Anchor Points. J. Res. Crime Delinquency 48, 33-57. https://doi.org/10.1177/0022427810384135

3. Boessen, A., Hipp, J.R., 2018. Parks as crime inhibitors or generators: Examining parks and the role of their nearby context. Soc. Sci. Res. 76, 186-201. https://doi.org/10.1016/j.ssresearch.2018.08.008

4. Boivin, R., D'Elia, M., 2017. A Network of Neighborhoods: Predicting Crime Trips in a Large Canadian City. J. Res. Crime Delinquency 54, 824-846. https://doi.org/10.1177/0022427817705935

5. Bowers, K., 2014. Risky Facilities: Crime Radiators or Crime Absorbers? A Comparison of Internal and External Levels of Theft. J. Quant. Criminol. 30, 389-414. https://doi.org/10.1007/s10940-013-9208-z

6. Brantingham, Patricia, Brantingham, Paul, 1995. Crime generators and crime attractors. Eur. J. Crim. Policy Res. 3, 5-26.

7. Breetzke, G.D., Fabris-Rotelli, I., Modiba, J., Edelstein, I.S., 2019. The proximity of sexual violence to schools: evidence from a township in South Africa. GeoJournal. https://doi.org/10.1007/s10708-019-10093-3

8. Cohen, J., Gorr, W.L., Olligschlaeger, A.M., 2007. Leading indicators and spatial interactions: A crime-forecasting model for proactive police deployment. Geogr. Anal. 39, 105-127. https://doi.org/10.1111/j.1538-4632.2006.00697.x

9. Connealy, N.T., 2019. Can we Trust Crime Predictors and Crime Categories? Expansions on the Potential Problem of Generalization. Appl. Spat. Anal. Policy. https://doi.org/10.1007/s12061019-09323-5 
10. Contreras, C., 2017. Block-Level Analysis of Medical Marijuana Dispensaries and Crime in the City of Los Angeles. Justice Q. 34, 1069-1095. https://doi.org/10.1080/07418825.2016.1270346

11. Demeau, E., Parent, G., 2018. Impacts of Crime Attractors and Generators on Criminality in Montreal. Can. J. Criminol. Crim. Justice 60, 387-412. https://doi.org/10.3138/cjccj.20170028.r1

12. Drawve, G., Moak, S., Berthelot, E., 2016. Predictability of gun crimes: a comparison of hotspot and risk terrain modelling techniques. Polic. Soc. 26, 312-331.

13. Feng, J.X., Liu, L., Long, D.P., Liao, W.W., 2019. An Examination of Spatial Differences between Migrant and Native Offenders in Committing Violent Crimes in a Large Chinese City. Isprs Int. J. Geo-Inf. 8. https://doi.org/10.3390/ijgi8030119

14. Frank, R., Andresen, M.A., Cheng, C., Brantingham, P., 2011a. Finding Criminal Attractors Based on Offenders' Directionality of Crimes, in: 2011 European Intelligence and Security Informatics Conference. Presented at the 2011 European Intelligence and Security Informatics Conference (EISIC), IEEE, Athens, Greece, pp. 86-93. https://doi.org/10.1109/EISIC.2011.34

15. Frank, R., Dabbaghian, V., Reid, A., Singh, S., Cinnamon, J., Brantingham, P., 2011b. Power of Criminal Attractors: Modeling the Pull of Activity Nodes. Jasss- J. Artif. Soc. Soc. Simul. 14. https://doi.org/10.18564/jasss.1734

16. Groff, E., McCord, E.S., 2012. The role of neighborhood parks as crime generators. Secur. J. 25, 1-24. https://doi.org/10.1057/sj.2011.1

17. Han, S., Nobles, M.R., Piquero, A.R., Piquero, N.L., 2019. Crime Risks Increase in Areas Proximate to Theme Parks: A Case Study of Crime Concentration in Orlando. Justice Q. 1-20. https://doi.org/10.1080/07418825.2019.1677935

18. Hewitt, A.N., Beauregard, E., Andresen, M.A., Brantingham, P.L., 2018. Identifying the nature of risky places for sexual crime: The applicability of crime pattern and social disorganization 
theories in a Canadian context. J. Crim. Justice 57, 35-46. https://doi.org/10.1016/j.jcrimjus.2018.03.003

19. Houser, K.A., McCord, E.S., Sorg, E.T., 2019. The Multilevel Impacts of Proximate Crime Generators and Attractors on Individual-Level Perceptions of Crime Risk. Crime Delinquency 65, 1798-1822. https://doi.org/10.1177/0011128718763129

20. Hsu, K.H., Miller, J., 2017. Assessing the Situational Predictors of Drug Markets across Street Segments and Intersections. J. Res. Crime Delinquency 54, 902-929. https://doi.org/10.1177/0022427817714574

21. Irvin-Erickson, Y., La Vigne, N., 2015. A Spatio-temporal Analysis of Crime at Washington, DC Metro Rail: Stations' Crime-generating and Crime-attracting Characteristics as Transportation Nodes and Places. Crime Sci. 4. https://doi.org/10.1186/s40163-015-0026-5

22. Iwanski, N., Frank, R., Reid, A., Dabbaghian, V., 2012. A computational model for predicting the location of crime attractors on a road network. Presented at the 2012 European intelligence and security informatics conference, IEEE, pp. 60-67.

23. Kimpton, A., Corcoran, J., Wickes, R., 2017. Greenspace and Crime: An Analysis of Greenspace Types, Neighboring Composition, and the Temporal Dimensions of Crime. J. Res. Crime Delinquency 54, 303-337. https://doi.org/10.1177/0022427816666309

24. Kinney, J., Brantingham, P., Wushcke, K., Kirk, M., Brantingham, P., 2008. Crime Attractors, Generators and Detractors: Land Use and Urban Crime Opportunities. Built Environ. 34, 6274.

25. Kurland, J., Johnson, S.D., Tilley, N., 2014. Offenses around Stadiums: A Natural Experiment on Crime Attraction and Generation. J. Res. Crime Delinquency 51, 5-28. https://doi.org/10.1177/0022427812471349

26. LaRue, E., Andresen, M.A., 2015. Spatial Patterns of Crime in Ottawa: The Role of Universities. Can. J. Criminol. Crim. Justice 57, 189-214. https://doi.org/10.3138/cjccj.2013.E47 
27. LeBeau, J.L., 2012. Sleeping with strangers: hotels and motels as crime attractors and crime generators, in: Patterns, Prevention, and Geometry of Crime. Routledge, pp. 99-124.

28. Mago, V.K., Frank, R., Reid, A., Dabbaghian, V., 2014. The strongest does not attract all but it does attract the most - evaluating the criminal attractiveness of shopping malls using fuzzy logic. Expert Syst. 31, 121-135. https://doi.org/10.1111/exsy.12015

29. Malleson, N., Andresen, M.A., 2016. Exploring the impact of ambient population measures on London crime hotspots. J. Crim. Justice 46, 52-63. https://doi.org/10.1016/j.jcrimjus.2016.03.002

30. McCord, E.S., Ratcliffe, J.H., 2007. A micro-spatial analysis of the demographic and criminogenic environment of drug markets in Philadelphia. Aust. N. Z. J. Criminol. 40, 43-63. https://doi.org/10.1375/acri.40.1.43

31. McCord, E.S., Ratcliffe, J.H., Garcia, R.M., Taylor, R.B., 2007. Nonresidential crime attractors and generators elevate perceived neighborhood crime and incivilities. J. Res. Crime Delinquency 44, 295-320. https://doi.org/10.1177/0022427807301676

32. Newton, A., 2018. Macro-level generators of crime, including parks, stadiums, and transit stations, in: The Oxford Handbook of Environmental Criminology.

33. Osborne, D., McCord, E.S., Higgins, G.E., 2016. The Interactive Influence of Prosocial Places, Youth Population, and Poverty on Incidents of Violent Assault. Deviant Behav. 37, 385-400. https://doi.org/10.1080/01639625.2015.1026772

34. Piza, E.L., Gilchrist, A.M., 2018. Measuring the effect heterogeneity of police enforcement actions across spatial contexts. J. Crim. Justice 54, 76-87. https://doi.org/10.1016/j.jcrimjus.2017.12.007

35. Ratcliffe, J., 2012. How near is near? Quantifying the spatial influence of crime attractors and generators., in: Andresen, M., Kinney, B. (Eds.), Patterns, Prevention and Geometry of Crime, Crime Science. Routledge, USA, Canada. 
36. Reid, A.A., Frank, R., Iwanski, N., Dabbaghian, V., Brantingham, P., 2014. Uncovering the Spatial Patterning of Crimes: A Criminal Movement Model (CriMM). J. Res. Crime Delinquency 51, 230-255. https://doi.org/10.1177/0022427813483753

37. Roman, C., Reid, S., Bhati, A., Tereshchenko, B., 2008. Alcohol Outlets as Attractors of Violence and Disorder: A Closer Look at the Neighborhood Environment. The Urban Institute.

38. Sheard, M., 1998. The elite arcade: Taming a crime generator. Reducing Crime Disord. Arcade Delta Police Dep. Herman Goldstein Award Final.

39. Song, G.W., Bernasco, W., Liu, L., Xiao, L.Z., Zhou, S.H., Liao, W.W., 2019. Crime Feeds on Legal Activities: Daily Mobility Flows Help to Explain Thieves' Target Location Choices. J. Quant. Criminol. 35, 831-854. https://doi.org/10.1007/s10940-019-09406-z

40. Song, J., Andresen, M.A., Brantingham, P.L., Spicer, V., 2017. Crime on the edges: patterns of crime and land use change. Cartogr. Geogr. Inf. Sci. 44, 51-61. https://doi.org/10.1080/15230406.2015.1089188

41. Song, J., Spicer, V., Brantingham, P., Frank, R., 2013. Crime Ridges: Exploring the Relationship between Crime Attractors and Offender Movement. IEEE, pp. 75-82. https://doi.org/10.1109/EISIC.2013.18

42. Sosa, V., Bichler, G., Quintero, L., 2019. Yelping about a good time: casino popularity and crime. Crim. Justice Stud. 32, 140-164. https://doi.org/10.1080/1478601X.2019.1600820

43. Soto, C., Summers, L., 2018. Macro-brothels as crime attractors: Impact of closure, displacement, and diffusion of benefits. Eur. J. Criminol. 147737081878801. https://doi.org/10.1177/1477370818788011

44. Tillyer, M.S., Wilcox, P., Walter, R.J., 2020. Crime generators in context: examining 'place in neighborhood'propositions. J. Quant. Criminol. 1-30.

45. Tita, G., Ridgeway, G., 2007. The impact of gang formation on local patterns of crime. J. Res. Crime Delinquency 44, 208-237. https://doi.org/10.1177/0022427806298356 
46. Vandeviver, C., Bernasco, W., Van Daele, S., 2019. Do sports stadiums generate crime on days without matches? A natural experiment on the delayed exploitation of criminal opportunities. Secur. J. 32, 1-19. https://doi.org/10.1057/s41284-018-0142-5

47. Xu, J., Griffiths, E., 2017. Shooting on the Street: Measuring the Spatial Influence of Physical Features on Gun Violence in a Bounded Street Network. J. Quant. Criminol. 33, 237-253. https://doi.org/10.1007/s10940-016-9292-y

48. Yoo, Y., Wheeler, A.P., 2019. Using risk terrain modeling to predict homeless related crime in Los Angeles, California. Appl. Geogr. 109. https://doi.org/10.1016/j.apgeog.2019.102039 


\section{REFERENCES}

Adams, W., Felson, M., 2015. Are Parks Crime Generators? An Exploratory Analysis of Crime and Parks in Houston, Texas.

Boessen, A., Hipp, J.R., 2018. Parks as crime inhibitors or generators: Examining parks and the role of their nearby context. Soc. Sci. Res. 76, 186-201. https://doi.org/10.1016/j.ssresearch.2018.08.008

Boivin, R., D'Elia, M., 2017. A Network of Neighborhoods: Predicting Crime Trips in a Large Canadian City. J. Res. Crime Delinquency 54, 824-846. https://doi.org/10.1177/0022427817705935

Bowers, K., 2014. Risky Facilities: Crime Radiators or Crime Absorbers? A Comparison of Internal and External Levels of Theft. J. Quant. Criminol. 30, 389-414. https://doi.org/10.1007/s10940013-9208-z

Brantingham, Patricia, Brantingham, Paul, 1995. Crime generators and crime attractors. Eur. J. Crim. Policy Res. 3, 5-26.

Breetzke, G.D., Fabris-Rotelli, I., Modiba, J., Edelstein, I.S., 2019. The proximity of sexual violence to schools: evidence from a township in South Africa. GeoJournal. https://doi.org/10.1007/s10708-019-10093-3

Clarke, R., Eck, J., 2003. Become a Problem Solving Crime Analyst in 55 Small Steps. Jill Dando Institute of Crime Science, London.

Contreras, C., 2017. Block-Level Analysis of Medical Marijuana Dispensaries and Crime in the City of Los Angeles. Justice Q. 34, 1069-1095. https://doi.org/10.1080/07418825.2016.1270346

Davies, T., Birks, D., 2021. Generating Crime Generators, in: Gerritsen, C., Elffers, H. (Eds.), AgentBased Modelling for Criminological Theory Testing and Development, Crime Science. Routledge, London and New York, pp. 13-44.

Demeau, E., Parent, G., 2018. Impacts of Crime Attractors and Generators on Criminality in Montreal. Can. J. Criminol. Crim. Justice 60, 387-412. https://doi.org/10.3138/cjccj.20170028.r1

Drawve, G., Moak, S., Berthelot, E., 2016. Predictability of gun crimes: a comparison of hotspot and risk terrain modelling techniques. Polic. Soc. 26, 312-331.

Feng, J.X., Liu, L., Long, D.P., Liao, W.W., 2019. An Examination of Spatial Differences between Migrant and Native Offenders in Committing Violent Crimes in a Large Chinese City. Isprs Int. J. Geo-Inf. 8. https://doi.org/10.3390/ijgi8030119

Frank, R., Andresen, M.A., Cheng, C., Brantingham, P., 2011a. Finding Criminal Attractors Based on Offenders' Directionality of Crimes, in: 2011 European Intelligence and Security Informatics Conference. Presented at the 2011 European Intelligence and Security Informatics Conference (EISIC), IEEE, Athens, Greece, pp. 86-93. https://doi.org/10.1109/EISIC.2011.34

Frank, R., Dabbaghian, V., Reid, A., Singh, S., Cinnamon, J., Brantingham, P., 2011b. Power of Criminal Attractors: Modeling the Pull of Activity Nodes. Jasss- J. Artif. Soc. Soc. Simul. 14. https://doi.org/10.18564/jasss.1734

Groff, E., McCord, E.S., 2012. The role of neighborhood parks as crime generators. Secur. J. 25, 1-24. https://doi.org/10.1057/sj.2011.1

Han, S., Nobles, M.R., Piquero, A.R., Piquero, N.L., 2019. Crime Risks Increase in Areas Proximate to Theme Parks: A Case Study of Crime Concentration in Orlando. Justice Q. 1-20. https://doi.org/10.1080/07418825.2019.1677935

Hewitt, A.N., Beauregard, E., Andresen, M.A., Brantingham, P.L., 2018. Identifying the nature of risky places for sexual crime: The applicability of crime pattern and social disorganization theories in a Canadian context. J. Crim. Justice 57, 35-46.

https://doi.org/10.1016/j.jcrimjus.2018.03.003 
Irvin-Erickson, Y., La Vigne, N., 2015. A Spatio-temporal Analysis of Crime at Washington, DC Metro Rail: Stations' Crime-generating and Crime-attracting Characteristics as Transportation Nodes and Places. Crime Sci. 4. https://doi.org/10.1186/s40163-015-0026-5

Iwanski, N., Frank, R., Reid, A., Dabbaghian, V., 2012. A computational model for predicting the location of crime attractors on a road network. Presented at the 2012 European intelligence and security informatics conference, IEEE, pp. 60-67.

Kimpton, A., Corcoran, J., Wickes, R., 2017. Greenspace and Crime: An Analysis of Greenspace Types, Neighboring Composition, and the Temporal Dimensions of Crime. J. Res. Crime Delinquency 54, 303-337. https://doi.org/10.1177/0022427816666309

Kurland, J., Johnson, S.D., Tilley, N., 2014. Offenses around Stadiums: A Natural Experiment on Crime Attraction and Generation. J. Res. Crime Delinquency 51, 5-28. https://doi.org/10.1177/0022427812471349

LaRue, E., Andresen, M.A., 2015. Spatial Patterns of Crime in Ottawa: The Role of Universities. Can. J. Criminol. Crim. Justice 57, 189-214. https://doi.org/10.3138/cjccj.2013.E47

LeBeau, J.L., 2012. Sleeping with strangers: hotels and motels as crime attractors and crime generators, in: Patterns, Prevention, and Geometry of Crime. Routledge, pp. 99-124.

Mago, V.K., Frank, R., Reid, A., Dabbaghian, V., 2014. The strongest does not attract all but it does attract the most - evaluating the criminal attractiveness of shopping malls using fuzzy logic. Expert Syst. 31, 121-135. https://doi.org/10.1111/exsy.12015

Malleson, N., Andresen, M.A., 2016. Exploring the impact of ambient population measures on London crime hotspots. J. Crim. Justice 46, 52-63. https://doi.org/10.1016/j.jcrimjus.2016.03.002

McCord, E.S., Ratcliffe, J.H., 2007. A micro-spatial analysis of the demographic and criminogenic environment of drug markets in Philadelphia. Aust. N. Z. J. Criminol. 40, 43-63. https://doi.org/10.1375/acri.40.1.43

McCord, E.S., Ratcliffe, J.H., Garcia, R.M., Taylor, R.B., 2007. Nonresidential crime attractors and generators elevate perceived neighborhood crime and incivilities. J. Res. Crime Delinquency 44, 295-320. https://doi.org/10.1177/0022427807301676

Munn, Z., Peters, M.D.J., Stern, C., Tufanaru, C., McArthur, A., Aromataris, E., 2018. Systematic review or scoping review? Guidance for authors when choosing between a systematic or scoping review approach. BMC Med. Res. Methodol. 18, 143. https://doi.org/10.1186/s12874-018-0611-x

Newton, A., 2018. Macro-level generators of crime, including parks, stadiums, and transit stations, in: The Oxford Handbook of Environmental Criminology.

Piza, E.L., Gilchrist, A.M., 2018. Measuring the effect heterogeneity of police enforcement actions across spatial contexts. J. Crim. Justice 54, 76-87. https://doi.org/10.1016/j.jcrimjus.2017.12.007

Reid, A.A., Frank, R., Iwanski, N., Dabbaghian, V., Brantingham, P., 2014. Uncovering the Spatial Patterning of Crimes: A Criminal Movement Model (CriMM). J. Res. Crime Delinquency 51, 230-255. https://doi.org/10.1177/0022427813483753

Roncek, D.W., Maier, P.A., 1991. BARS, BLOCKS, AND CRIMES REVISITED: LINKING THE THEORY OF ROUTINE ACTIVITIES TO THE EMPIRICISM OF “HOT SPOTS"*. Criminology 29, 725-753. https://doi.org/10.1111/j.1745-9125.1991.tb01086.x

Sheard, M., 1998. The elite arcade: Taming a crime generator. Reducing Crime Disord. Arcade Delta Police Dep. Herman Goldstein Award Final.

Song, G.W., Bernasco, W., Liu, L., Xiao, L.Z., Zhou, S.H., Liao, W.W., 2019. Crime Feeds on Legal Activities: Daily Mobility Flows Help to Explain Thieves' Target Location Choices. J. Quant. Criminol. 35, 831-854. https://doi.org/10.1007/s10940-019-09406-z

Song, J., Andresen, M.A., Brantingham, P.L., Spicer, V., 2017. Crime on the edges: patterns of crime and land use change. Cartogr. Geogr. Inf. Sci. 44, 51-61. https://doi.org/10.1080/15230406.2015.1089188 
Song, J., Spicer, V., Brantingham, P., Frank, R., 2013. Crime Ridges: Exploring the Relationship between Crime Attractors and Offender Movement. IEEE, pp. 75-82. https://doi.org/10.1109/EISIC.2013.18

Sosa, V., Bichler, G., Quintero, L., 2019. Yelping about a good time: casino popularity and crime. Crim. Justice Stud. 32, 140-164. https://doi.org/10.1080/1478601X.2019.1600820

Tillyer, M.S., Wilcox, P., Walter, R.J., 2020. Crime generators in context: examining 'place in neighborhood'propositions. J. Quant. Criminol. 1-30.

Tita, G., Ridgeway, G., 2007. The impact of gang formation on local patterns of crime. J. Res. Crime Delinquency 44, 208-237. https://doi.org/10.1177/0022427806298356

Tricco, A., 2017. Part 4: Doing scoping reviews, Scoping reviews: what they are and how you can do them. Li Ka Shing Knowledge Institute, St. Michael's Hospital.

Vandeviver, C., Bernasco, W., Van Daele, S., 2019. Do sports stadiums generate crime on days without matches? A natural experiment on the delayed exploitation of criminal opportunities. Secur. J. 32, 1-19. https://doi.org/10.1057/s41284-018-0142-5

$\mathrm{Xu}$, J., Griffiths, E., 2017. Shooting on the Street: Measuring the Spatial Influence of Physical Features on Gun Violence in a Bounded Street Network. J. Quant. Criminol. 33, 237-253. https://doi.org/10.1007/s10940-016-9292-y

Yoo, Y., Wheeler, A.P., 2019. Using risk terrain modeling to predict homeless related crime in Los Angeles, California. Appl. Geogr. 109. https://doi.org/10.1016/j.apgeog.2019.102039 